\title{
Exploring the Genre of Academic Oral Presentations: A Critical Review
}

\author{
Kuldip Kaur ${ }^{1}$, Afida Mohamad Ali²* \\ ${ }^{1}$ Academy of Language Studies, Universiti Teknologi MARA Malaysia, KM26, Jalan Lendu, 78000 Alor Gajah, Melaka, Malaysia \\ ${ }^{2}$ Department of English, Faculty of Modern Languages and Communication, Universiti Putra Malaysia, Malaysia \\ Corresponding Author: Afida Mohamad Ali, E-mail: afida@upm.edu.my
}

\section{ARTICLE INFO}

\section{Article history}

Received: August 14, 2017

Accepted: October 25, 2017

Published: January 05, 2018

Volume: 7 Issue: 1

Advance access: December 2017

Conflicts of interest: None

Funding: None

\begin{abstract}
Conducting Academic Oral Presentation (AOP) is an endeavour for undergraduates although it is a key academic genre for undergraduates. Despite its importance, there remains a paucity of studies on this oral genre in the Malaysian context as shown in the body of the literature. This paper provides a critical review of the literature on AOP and discusses the advantages and limitations of the previous studies to date on this oral genre. The literature shows most studies that adopt the genre analysis approach typically analyse only one section of the oral genre. These studies have not examined the AOP rhetorical structure in totality. Moreover, studies on multimodal analysis of AOP comparing the verbal and non-verbal modes are limited. Only few studies have attempted to examine the juxtaposition of the moves, linguistic elements and the visuals. AOPs are ubiquitous for the students across various courses and disciplines in the university and past studies have also compared the differences between disciplines (Zappa-Hollman, 2007; Morita, 2000). Thus, realizing the importance of AOP, clearly there is a necessity to conduct more research in this area in the local context.
\end{abstract}

Key words: Academic oral presentations, Genre, Linguistic features, Multimodality

\section{INTRODUCTION}

This paper reviews the literature on studies relating to AOPs. Academic oral presentation (henceforth AOP) is an important academic discourse for undergraduates and has been explored by several researchers. Unlike academic writing that has been greatly explored, less attention has been given to AOP (Barrett \& Liu, 2016; Yang, 2014, Bu 2014; Morita, 2004, Carter-Thomas \& Rowley-Jolivet, 2003; Ventola et al, 2002; Zappa-Hollman, 2001). This is because of the dialogic nature of the oral presentation and difficulty in collecting, transcribing and analysing large amounts of recorded data. Moreover, collecting such data is also tedious as it involves audio or video recording which may turn out not to be clear in the end. Most of the studies conducted on AOPs were mainly on ESL learners in foreign contexts. However, studies on Academic Oral Presentation in Malaysia have emerged in recent years. These previous studies focussed on challenges in giving oral presentations (Mariana \& Siti Akmar, 2013; Noor Hashimah Abd Aziz, 2007), genre analysis of Question $\&$ Answer sessions of AOP (Seliman and Noor Izzati, 2010), genre analysis of engineering oral presentations (Seliman, 1996) and communication apprehension (Suryani Sabri \& Teah 2014; Mohd Azrizal, 2014; Noor Raha \& Sarjit, 2011). Studies to date which have been conducted at the tertiary level have focused on various aspects such as feedback, assessments, anxiety, rhetorical structure, linguistic features, challenges and oral communication needs. Whereas the past studies have been valuable in their own way, the focus has been mainly on one section of the AOP genre. There are very limited studies that have examined the whole rhetorical structure of the AOP which includes the introduction, body, conclusion and question and answer sessions. By establishing the rhetorical structure in totality it helps academics to acquaint their students with the oral discourse. The verbal and non-verbal modes are also important when analysing the generic characterization of the AOP. By having these elements analysed alongside the moves, it provides a wholesome or comprehensive picture of the AOP genre.

This paper focuses on studies on AOP from a genre perspective. Through a review of such studies, the themes and limitations of past studies and suggestions for further research are given. In order to know more about AOP, it will be appropriate to establish a description of this oral genre in the following section.

\section{DEFINITION OF AOP}

Academic oral presentation is an academic discourse which is conducted in the university to show undergraduates' understanding of a subject to the audience. Within the English language course (EAP, EOP or ESP) and discipline-based courses offered at universities, the AOP is used as part of the assessment, present research projects, and socialize students into the academic discourse community (Zareva, 2011; Duff, 2010; Zappa-Hollman, 2007; Morita, 
2000). Academic oral presentations have been defined by various scholars. The definition of the term AOP in this study refers to any oral presentation where the undergraduates have to present on a given topic in their classrooms. Ming (2005) defined oral presentation as "partly spoken and partly visual form of communication' (p.118) which usually has a time limit and happens in organizational settings. Likewise, Baker (2000) claims oral presentations are like formal conversations which are structured and have a time frame. Presenters can use visual aids in their presentations and at the end respond to questions given by the audience. Morita (2000) describes AOPs as 'routined' activities in university and are established as a formal oral assessment to show the development of certain skills. For Mandal (2000) oral presentations are 'speech in a business, technical, professional or scientific environment'(p.8). Oral presentations are like lectures, a monologic discourse that deals with information transfer and have informal and conversational expressions of seminars (Hyland, 2009). He further adds that such presentations are usually very informal, audience friendly and extremely challenging for non-native English speakers. In brief, AOP for undergraduates is a classroom genre where students are expected to display their knowledge of the discipline as expected by the discourse community. The following sections provide a critical overview of issues that have been studied by scholars regarding AOP.

\section{BENEFITS OF AOP}

There are enormous benefits of AOP as shown in the literature. Among the benefits of oral presentations is the use of the four language skills (Al Issa \& Al-Qutban, 2010; King, 2002). It prepares students for real life or for the job market in the future. Zappa-Hollman (2001) and Morita (2000) report how academic presentations help students gain membership and competence within their academic communities. For Girard, Pinar and Trupp (2011), AOPs allow students to interact and be more active in the classroom thus motivating them to learn English. AOP gives practice in speaking as students are compelled to communicate with others and learn from them. Similarly, Hovane (2007) concurs that such oral task can also provide opportunities for students to have control of content as well as the flow of the classroom. This leads to autonomous learning (King, 2002).

Additionally, AOP can motivate students to communicate and enable them to transfer their knowledge in regards to academic communication to the outside world (Zivkovic, 2015; Zareva, 2009). Various studies have shown how AOP enhances teamwork (Yang, 2010; Chou, 2011 and Zivkovic, 2014). Other benefits include develop confidence (King, 2002; Nor Fathiah and Gurnam, 2013), provide authentic practice of English and improve their communication skills. Finally, undergraduates benefit from oral presentations which help them develop and integrate soft skills such as team work, critical thinking skills, presentation skills, leadership skills, time management skills and interpersonal skills.

\section{CHALLENGES IN AOP}

Despite being prevalent, many ESL undergraduates consider AOP as one of the most challenging academic tasks. Various studies have reported on the challenges faced by students in giving oral presentations (Ferris and Tagg, 1996; Weissberg; 1993; Tracy, 1997; Morita, 2000; King; 2002; Otoshi and Hefferman, 2008; Yang, 2010, Bankowski, 2010; Chen, 2011; Noor Raha and Sarjit, 2011; Hafner \& Miller, 2011; Mahani, et al (2014). This oral discourse is reported to be the most stressful communicative event as studies have indicated (Vitasari et al, 2010; Noor Raha \& Sarjit, 2011; Suryani Sabri \& Teah, 2014). The most difficult part is presenting in English especially for those less proficient students who eventually end up reading from the visuals. Thus language deficiency is one of the main challenges for ESL students in AOPs. No doubt being an effective presenter depends on natural ability, however, the more the presenter practices the better the speaker becomes. Weisseberg (1993) contended that lack of linguistic knowledge was among the challenges faced by NNS in his study. Hence, they tend to resort to L1 when explaining as Huang (2006) revealed in his study.

Another challenge in AOP is speech anxiety. Various studies have investigated this aspect of oral presentations. Noor Raha and Sarjit's (2011) study on technical oral presentation among Malaysian engineering undergraduates found that students' self-perception of low English language proficiency led to high levels of anxiety. They reported that anxiety was also caused by limited technical knowledge of the subject and the audience. Students' lack of academic and research training also contributed to high anxiety in AOPs.

Lack of confidence to speak in English in AOPs imposes the greatest challenge for ESL learners. They lack the confidence to speak to a live audience where they have to respond spontaneously to questions. (Morita, 2000; Woodrow, 2006; Vitasari et al, 2010; Noor Raha \& Sarjit, 2011). Studies show how the students find it challenging to engage with the audience in discussions (Weissberg, 1993; Zappa-Hollman, 2007; Yang, 2010, Aguilar, 2004). They feel under great pressure because of the presence of experts. The students also dread Q \& A sessions in oral presentations as they fear being asked questions while the audience too does not know how to ask questions and just kept quiet (Seliman and Noor Izzati, 2010, Nor Fathiah and Gurnam, 2013). There are also incorrect pronunciation woes among ESL learners in relation to AOPs.

Other challenges in AOP include working in groups (Chou, 2011), choosing appropriate topic and making notes (Yang, 2010), foreign culture (Yang 2010; Morita, 2004; Zappa-Hollman, 2001) and differences in expectations of student AOP between language instructors and content experts (Ferris, and Tagg, 1996; Weisseberg, 1993; Bhattacharyya \& Zullina, 2012). What past studies indicate about oral presentations is that this genre is challenging for ESL learners and is even more demanding as nowadays undergraduates are expected to employ technology and thus have attractive visuals. Eventually, students end up spending more time preparing for their visuals (Yates and Orlikowski, 2007) or depend on them greatly if they have language deficiencies. 
This then defeats the purpose of AOP which is for undergraduates to communicate effectively and confidently to an audience. Studies on AOP have adopted the genre approach, multimodality approach or corpus analysis approach to analyse this discourse. The following section briefly provides the literature of the genre analysis approach.

\section{ANALYSIS OF ACADEMIC ORAL PRESENTATION AS A GENRE}

Genre refers to spoken or written discourse with or without literary aspirations (Swales, 1990, p.35). He defines genre as a communicative event with a set of communicative purposes established by expert members of the discourse community in which it occurs. This term was later expanded by Bhatia (1993) which includes target audience, form, medium, and content which has an influence on a genre. In the genre analysis approach important terms are 'move' and 'sub-move' or 'step'. A 'move is a part of a spoken or written text to fulfil a communicative purpose and is defined as a basic unit for analysing text. A 'step' is similar to a move but Swales used the term 'sub-moves' in his model which is similar in function. Thompson (1994) uses the term 'function' and 'sub-functions' in her study on academic lectures while Bhatia (1993) uses the term 'strategy' used by a speaker or writer. However, these terms have almost similar connotations.

Genre analysis has focused mainly on academic writing and less on AOP. In the last two decades, ESP studies focussed more on written text rather than spoken text. Hewings (2002) believes this could be due to the difficulties in data collection and analysis. He reports that ESP research on written text is far more than spoken text whereby $86 \%$ is written and $14 \%$ is spoken data. Dudley-Evans (2004) admits lack of such spoken data can be problematic. A point highlighted by Hewings (2002) was that in most target situations, speech is more important for example, listening to lectures, participating in seminars, and giving oral presentations. However, most genre studies have focused more on written text. A few studies on oral discourse especially oral presentations have been conducted based on the Swales (1990) genre approach.

Drawing on this notion of genre, Swales CARS framework has been adapted and applied by various scholars for exploring rhetorical moves in oral genre. Examples of spoken genres that have been examined are rhetorical structure of conference presentations (Dubois, 1980), introductions to university lectures (Thompson, 1994; Yaakob, 2013), lecture and poster sessions at conferences (Shalom, 1993), question and answer sessions in oral presentation (Seliman \& Noor Izzati, 2010), introduction section of conference presentation (Rowley-Jolivet \& Carter Thomas 2005), engineering oral presentation (Seliman, 1996), body section of oral reports (Seliman and Irwan Affendi, 2010) and conclusions of presentations (Kite, 2008).

\section{RHETORICAL MOVES IN ACADEMIC ORAL PRESENTATIONS}

Studies on rhetorical structure of oral presentations show differences in the introductions of conference presentations, lectures, and classroom presentations. Two studies on conference presentations closest to the present study are Dubois (1980) and Rowley-Jolivet \& Carter-Thomas (2005). Dubois's (1980) study was the pioneer in establishing rhetorical structure of oral presentations in a biomedical conference. Her study focused on the introduction, body and termination sections minus the question and answer session. The following moves were identified in her study.

For Rowley-Jolivet and Carter-Thomas (2005) AOPs have different rhetorical structure, vocabulary choice and style of delivery compared to other oral genres such as lectures, seminars or defense papers. For conference presentations, Rowley-Jolivet and Carter-Thomas (2005) established a clear rhetorical structure for the introduction section. In their study, 44 oral presentations at international scientific conferences by native speakers in three disciplines (geology, medicine, and physics) were analysed. Nine physics presentations were also compared with their corresponding published articles in the conference proceedings. The syntactic patterns of the written and verbal modes were compared and they found that conference presentations require certain structures. The rhetorical structure of conference presentation introduction pioneered by them has the following moves.

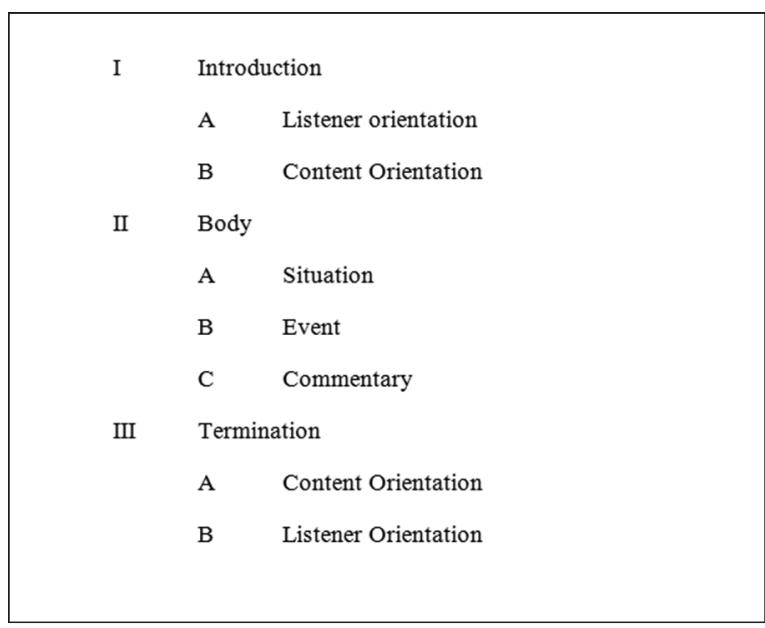

Moves of Biomedical Speeches by Dubois (1980)

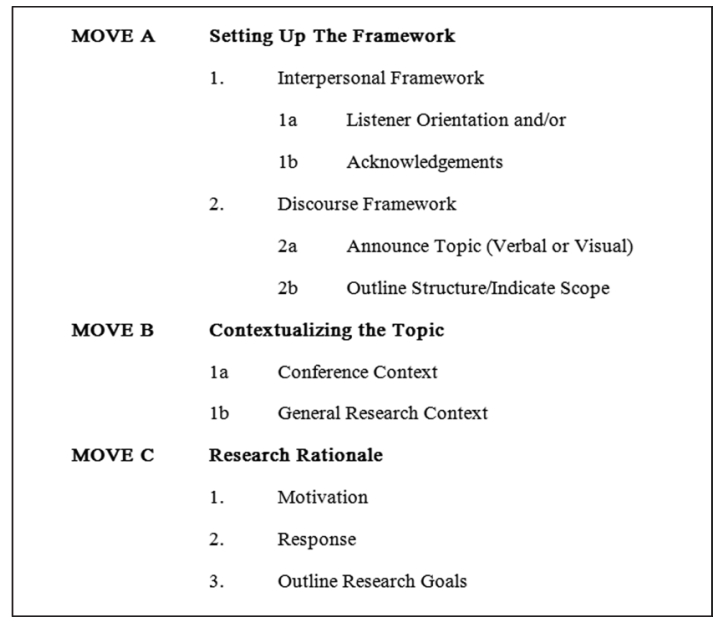

Moves in Introduction Section of Conference Presentations by Rowley-Jolivet \& Carter-Thomas (2005) 
This model was based on Swales (1990) CARS framework for research articles (RA) introductions. As shown above, there are three moves in the introduction of the conference presentations (CP). Move A 'Setting Up the Framework' has two sub-moves which are crucial in the CP context as there is a live audience. In the first sub-move 'Interpersonal Framework' there are two steps. The 'Listener Orientation' step is to address the audience, conference chairman, organisers, greeting and thanking them while 'acknowledgements' step is to thank the collaborators, companies or agencies who funded the research. The 'Discourse Framework' sub-move is to signal the organization of the oral presentation. This move is crucial as listeners need cues when listening and processing heavy information within the constraints of time. Thus, 'Announce the topic' and 'outlining structure' of talk can indicate to audience the topic that will be presented and aspects to be covered in the talk. For Move B 'Contextualising the topic' includes references to other talks in similar conference context or other research contexts generally. However, they caution the use of lengthy literature review as audience in conferences are mainly interested in knowing the latest information on a given topic. Moreover, there is time constraint in such conferences. In Move C 'Research Rationale' the three sub-moves concern the motivation of the research, the importance of the research and the goal of the research.

Another study which also investigated the rhetorical structure of oral presentation based on Swales moves is by Seliman (1996). Her study comprised 68 oral presentations by both novices and experts from the engineering discourse community. What is novel about Seliman's study is her move structure included the introduction, body and termination sections of the engineering oral presentation. In her study, for the introduction section she adopted Dubois' (1980) model, with some additional steps and reconstructed them. Very few studies have examined the body section of the oral genre. Seliman (1996) looked at rhetorical structure of engineering oral presentations. For the moves in the body of classroom oral presentation based on the literature review, it shows that the moves are determined by the content of the task. Seliman (1996) in her study on engineering students provided the following moves:

In another study, Mariana (2010) analysed the moves of oral presentations of 23 engineering graduates from four different faculties undergoing industrial training. She analysed the moves based on Seliman's (1996) moves and sub-moves. According to her, most engineering oral presentations adhered to the format prescribed for the introduction and termination sections where sub-moves such as 'greeting the audience' in the introduction section and 'thanking audience' at the termination section were relatively fixed. However, she highlights that it was not easy to determine the moves and sub-moves in the body or content section of the oral presentations mainly because of the differences in the requirements of the tasks set by the faculty. Thus, she claims that the moves in the body section relied on the requirement of the tasks as outlined in the assessment criteria. Overall, she concludes that students had knowledge of the structure of the engineering oral presentations or the 'script knowledge' thus they adhered to the prescribed moves that were fixed in a linear form from introduction, body, conclusion, and termination.

A study by Seliman and Irwan Affendi (2010) also investigated moves in the body section of oral presentation among engineering students. Based on their study the following moves were established.

In short, the studies that investigated the move of the body of oral presentations indicate that the moves are established based on the task or content of the task. There are no standardised fixed moves for this section of the AOP genre unlike the introduction, discussion or closing sections. Hence, most previous studies on rhetorical structure of the AOP have not examined this part of the oral genre.

For the pre-closing and closing section of the oral presentation, Kite (2008) establishes the following moves for an academic conference involving engineers.

Seliman's (1996) model of the conclusion section which she refers to as 'termination' has more moves and sub-moves and is considered more comprehensive than the model by Kite (2008). The termination moves identified and reported in her study are 'checking the time', 'hinting the coming of the end of the oral presentation', 'looking forward', 'tying up' and 'orientating the listeners'. The moves in her termination or conclusion section are more detailed unlike Kite's (2008) model.

In another study, Seliman and Noor Izzati (2010) conducted a study on moves in Question and Answer sessions of

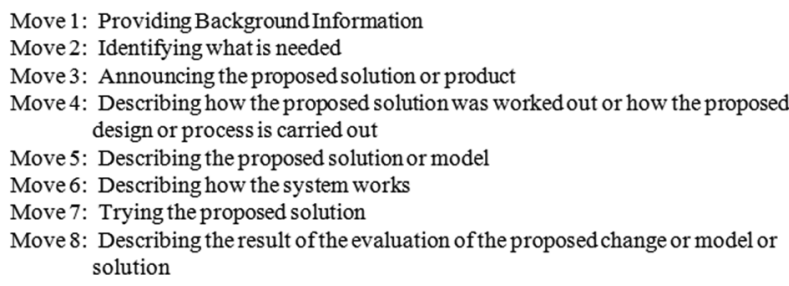
design or process is carried out

Move 5: Describing the proposed solution or mode

Move 6: Describing how the system works

Move 7: Trying the proposed solution

Move 8: Describing the result of the evaluation of the proposed change or model or solution

Moves in the Body of Engineering Oral Presen-tations

\begin{tabular}{|ll|}
\hline MOVE 1 & Stating intention of speech \\
MOVE 2 & Describing company and service provided \\
MOVE 3 & Giving detailed description of product/service \\
MOVE 4 & Explaining company structure \\
MOVE 5 & Giving reasons why audience must choose product/ \\
& service provided \\
MOVE 6 & Describing sales profile/company performance \\
MOVE 7 & Providing information on company strategy \\
MOVE 8 & Stating additional relevant information \\
MOVE 9 & Explaining company management position and roles \\
MOVE 10 & Giving explanation on personal role in company \\
& \\
\hline
\end{tabular}

Moves in Body of Oral Presentations (Seliman \& Irwan Affendi, 2010) 


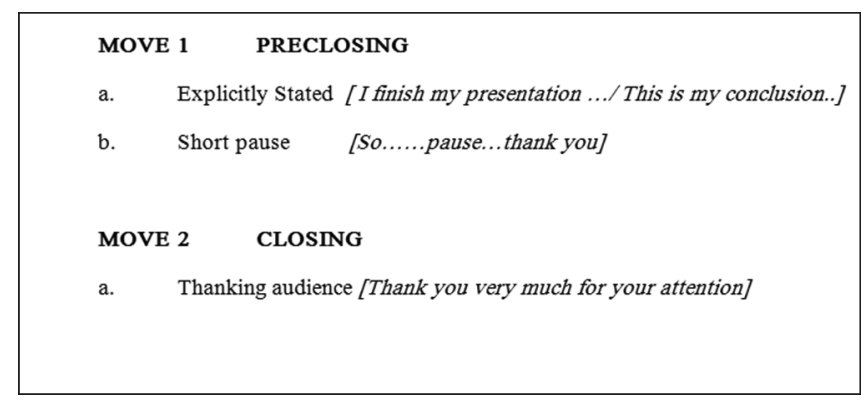

Moves in Closing Section of Oral Presentations

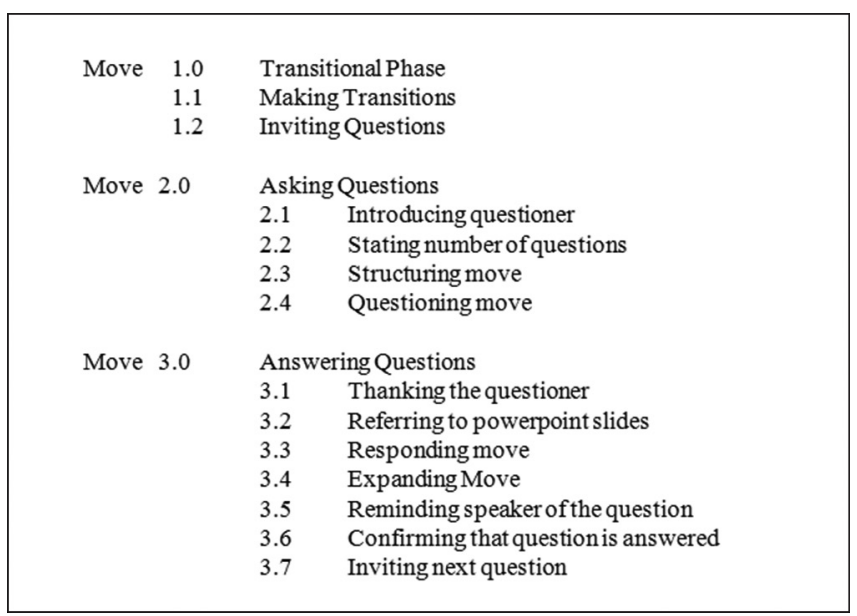

Moves in Q \& A Session of Oral Presentations

oral presentations. They found that there were differences in moves in the Q \& A session of 44 undergraduates from two different faculties enrolled in an English language course. The researchers conclude that there are specific moves utilised during the Q \& A session and this should be highlighted to undergraduates. They have identified the following moves in their study:

In another study, Aguilar (2004) investigates moves in peer seminar and reports that there is a pre-introduction move unlike other genres. Thus, she proposes a structure for the peer seminar which she claims is a hybrid of the lecture, the written research article and conference presentation. A recent study by Yu-jung and Hung-Tzu (2015) on 58 talks from TED conferences, examined moves with corpus based approach. Some of the setting in these studies is in the professional context such as conferences. In such situations, presenters are generally aware of the moves and being professionals they have less qualms. Adversely, classroom student AOPs are in an academic setting which involves novices and their instructors, who are also from the academic setting. The past studies reported mainly on AOPs involving professionals. Arguably, studies on AOP in an ESL context is scant.

The following table (See Table 1) summarizes the related studies on genre approach to oral presentations, poster presentations and seminars that involve students as presenters.

Other academic genres such as lectures have been analysed based on their functions and sub-functions or stages (Thompson, 1994; Lee, 2009 and Yaakob, 2013 on lecture introductions, Cheng, 2012 on lecture closings;
Lee, 2016 on classroom lessons). Lectures are considered academic oral presentations but they involve academics and not students hence the rhetorical structure of the lecture genre is for obvious reasons different from students presentations.

There are a number of drawbacks in the previous research. First, most of the genre studies covered only one section of the academic oral presentation. Most studies only seem to focus on introductions as it is easier to apply Swalesian moves. The moves of the AOP genre in social sciences were barely studied in totality. Secondly, the studies were mainly based on scientific disciplines or very discipline specific. Thirdly, most research have focused on conferences, graduate seminars, defense sessions where both presenters and audience are professionals, unlike classroom student presentations where the presenters, as well as the audience, are peers and novices. In other words more studies on professional setting and less on academic setting. Thus, the studies that investigated rhetorical structure of classroom student presentations are limited and those in the body of literature do not indicate if there are differences in the moves for AOPs in different courses. After all, the way one discipline uses a genre is not the same as another discipline using the similar genre. Moreover, it is important to investigate to what extent the generic competence acquired are transferable from one course to other courses in the discipline such as, in an EAP course to a discipline-based course. This is essential to help undergraduates gain success in the academia. Past studies lack this delineation which is very much needed.

Most studies conducted on academic oral presentations involved individual oral presentations (Rowley_Jolivet \& Carter-Thomas, 2005; Seliman 1996, Yaakob, 2013). However there are also studies that have investigated group presentations (Chou, 2011; Seliman \& Izzati, 2010; Zappa-Hollman, 2007; Morita, 2000). Previous studies on group oral presentations were either based on a discourse socialization perspective or focused on one section of the AOP. In group presentations there would be a transitional phase when speakers end their part of the presentation and hand over to the next speaker to continue. Seliman (1996) refers to the 'transitional phase' move in her Q and A section when a presentation ends and the 'questioning' move begins. However, previous studies have not reported on such moves which occur in the AOP. This is important to note as in group presentations there could be additional moves in the AOP rhetorical structure.

\section{LINGUISTIC FEATURES IN AOP}

In any oral or written genre, a presenter or writer needs to know the suitable linguistic expressions and effective strategies used to make their audience or readers understand the flow of the text. In AOPs, how presenters move from one slide to another can confuse audience (Anthony et al, 2007). In this regard, the choice of linguistic expressions can ensure smooth and clear AOPs. Thus, the linguistic features to realise the moves in the oral genre are equally important. Students need more specific language guidelines (Barrett \& Liu, 
2016) and few studies have investigated linguistic features in AOP among ESL learners. Previous studies that have investigated linguistic features in the oral genre include Rowley-Jolivet and Carter-Thomas (2005), Thompson (1994), Weissberg (1993), Cheng (2012), Zareva (2009, 2011, 2016), Fernandez-Polo (2014) and, Lee and Subtirelu (2015). These studies looked at formulaic expressions, lexical bundles, metadiscourse markers, stance, inversions, clauses, passive structures, personal pronouns, pseudo-clefts, adverbials, multi-word verbs and transition signals.

However, researchers have not investigated the use of metadiscourse features in academic oral genre such as AOPs in much detail. Metadiscourse studies in oral genre conducted to date include EAP lessons and university lectures (Lee \& Subtirelu, 2015), text structuring (Thompson, 2003), signalling transitions in OPs (Anthony et al, 2007; Kibler et al 2013,), interpersonal features in lectures (Lee, 2009; Morell, 2007), academic conference (Thompson, 2003), stance in academic speech (Yang, 2014), interactive strategies in students' academic presentations (Magnuczne Godo, 2011). Evidence suggests that metadiscourse features benefit listeners who can comprehend information presented $(\mathrm{Bu}, 2014$; Hyland, 2005). Therefore, exploring metadiscourse features in undergraduates' AOPs is needed to help them be better presenters. For Mauranen (2010), the role of metadiscourse is more crucial in spoken genre than written genre as managing spoken interaction is greater in 'real time' in front of audience. Thus, studies relating to linguistic features such as metadiscourse markers are equally important. Similarly formulaic expressions and lexical bundles are valuable for AOP and researchers have examined these in their studies (Lee, 2016; Yaakob, 2013).

In brief, the studies in the body of literature indicate the various specific linguistic features analysed in AOPs. Among the drawbacks of these studies is a tendency to analyse the linguistic features in certain sections of the genre while there are some that focused on certain features in the whole genre. The approach in analysing linguistic features also differed where some adopted the SFL approach and some used a corpus analysis approach. When it comes to AOPs, interest in interpersonal and interactive features is more prevalent as this is an integral factor that differentiates the oral genre from a written genre. In AOPs, the speakers have to deal with a live audience and have to make linguistic choices in order to connect with the audience. The linguistic realisations of each move in the AOP rhetorical structure should be highlighted to help speakers who are novices as they need the linguistic scaffolding. Thus, the shortcomings of the studies in the literature include analysis of linguistic elements in only one section of the AOP genre and looking at a specific linguistic feature such as adverbials, pronouns, and metadiscourse markers individually in all sections of the genre. It is suggested that studies on AOP should attempt to analyse the genre as a whole in order to widen the avenues for analysis.

\section{VISUALS IN AOP}

In oral presentations, a key component is visuals. The advent of technology affects AOPs as presenters nowadays are expected to deliver their speech using multimedia such as powerpoint software, videos, images and pictures (Bloch, 2013). Hence the emergence of the multimodality approach in AOPs. This approach to discourse examines how the various modes such as visuals, verbal, sounds, and gestures play a part to create a text. The visual mode is similar to verbal mode (Kress \& van Leeuwen, 1996, 2006). Visuals or images can capture attention of audience and convey a message effectively. Apart from verbal mode, the written, the non-verbal material and body language mode combination is used in oral presentations (Morell, 2015).

The importance of visuals in oral presentations is advocated by Dubois (1980) in her study on the use of slides in biomedical speeches. Slides display important information of the content of the speech which is not verbally delivered, reinforce important information and provide visual interest (Dubois, 1980). This was followed by more studies examining the use of visuals in oral presentations among them by Rowley-Jolivet (2002; 2012), Tardy (2005), Zareva (2013) and Morell (2015). The comparison between the visuals in PPT slides and verbal mode have also been examined to evaluate the effectiveness of visuals.

In her study, Rowley-Jolivet, (2002) examined visuals in scientific conference presentations in various areas. In total, 2048 visuals were examined and she classified them into four types of visuals namely scriptural, numerical, figurative and graphical. The most common visual form was scriptural visuals in scientific conferences as findings revealed. She highlights the importance of visuals and claims they depict the particular genre whether spoken or written. She concludes comprehension is greatly improved if focus is given to the visual conventions specific to the spoken genre and to the discipline. Visuals play a pertinent role in scientific discourse to provide information which is otherwise difficult to transmit via linguistic way.

Wecker (2012) and Rowley-Jolivet, (2012) investigated spoken text and written text on slides in academic context. Ayad and Akbar (2014) attempted to establish the generic structure of PPT presentations in a defense sessions Their study demonstrates differences in PPT conference presentations and PPT defense session presentations where some moves based on Swales (1990) CARS model are present in conference presentations but are absent in defense session. In their study, they also reported that presenters relied on visuals to illustrate their findings. Rowley-Jolivet (2015) examined conference presentations and their corresponding proceedings articles in engineering discipline and report how quantifiable data is handled differently in both spoken and written form. The visuals support numerical information which is complex for speakers to verbally comment and presenters have to select the numerical information for the audience and not bore them. Morell (2015) also compared oral presentations of hard sciences and soft sciences disciplines through a multimodal approach and showed that the hard sciences used more non-verbal resources while those in soft sciences used more verbal mode. She concurs that visuals can support the speaker, enhance verbal elaboration, used as a decorative or to contextualize the topic. These studies 
conclude that visuals play a significant role in oral presentations. In a recent study, Mestre-Mestre (2015) shows how students use different strategies when combining texts and images for communicating and depend on images mainly when they have to explain difficult concepts. She asserts that visuals are pertinent to support the delivery mode.

Based on past studies, it is evident that with digital technology, speakers are expected to use not just verbal mode but the visual mode in their AOPs. The studies show that the most common visual mode is the use of powerpoint slides.
Additionally, past studies have also reported on the types of visuals and their functions. Comparisons in the use of visuals between hard sciences and soft sciences have been made but not between courses. Another limitation is that the visuals in the AOPs examined were mainly from the science discipline. Very few studies have scarcely compared the differences in the verbal commentary and corresponding visuals against the moves in the rhetorical structure of the AOP. Visuals are part of the generic structure of AOPs and given the role that visuals play, there are still a dearth of studies in analysing

Table 1. Overview of the studies on genre approach to academic oral presentations

\begin{tabular}{|c|c|c|c|}
\hline Author & Year & Type of oral genre & Scope of study \\
\hline Dubois & 1980 & Conference presentation & Rhetorical structure \\
\hline Dubois & 1985 & Poster session & \\
\hline Weissberg & 1993 & Graduate seminar & Observation of features \\
\hline Seliman & 1996 & Engineering oal presentation & Rhetorical structure \\
\hline Aguilar & 2004 & Peer seminar & Rhetorical structure \\
\hline Rowley-Jolivet \& Carter Thomas & 2005 & Conference presentation & $\begin{array}{l}\text { Rhetorical structure } \\
\text { Use of pronouns }\end{array}$ \\
\hline Kite & 2008 & Academic conference & Rhetorical structure closing session language pattern \\
\hline Morton & 2009 & Student presentation & Rhetorical structure \\
\hline Wulff et al. & 2009 & Conference presentation & Rhetorical structure discussion session \\
\hline Seliman \& Irwan Affendi & 2010 & Classroom oral presentations & Rhetorical structure body session \\
\hline Seliman \& Noor Izzati & 2010 & Classroom oral presentations & Rhetorical structure question $\&$ answer session \\
\hline Mariana Yusoff & 2010 & Technical oral presentation & Rhetorical structure \\
\hline Yu-jung \& Hung-Tzu & 2015 & Conference presentation & Rhetorical structure \\
\hline
\end{tabular}

Table 2. Overview of the studies on visuals in academic oral presentations

\begin{tabular}{|c|c|c|}
\hline Author & Year & Findings \\
\hline Dubois & 1980 & Visuals can stand alone or accompany texts depending on the speaker's intentions \\
\hline Rowley-Jolivet & 2002 & $\begin{array}{l}\text { Non-verbal materials are used to structure discourse and express logical relations to } \\
\text { facilitate communication and create relationship with audience }\end{array}$ \\
\hline Charles \& Ventola & 2002 & $\begin{array}{l}\text { Slides used as illustrations in humanities while those from physical sciences used as } \\
\text { evidence providers }\end{array}$ \\
\hline Tardy & 2005 & PPT Slides project disciplinarity and individuality \\
\hline Wecker & 2012 & Concise slides with limited information have positive effects on audience's retention \\
\hline Rowley-Jolivet & 2012 & $\begin{array}{l}\text { Slides contain highly condensed expression while the presenter's verbal commentaries } \\
\text { are much more extended }\end{array}$ \\
\hline Querul-Julian \& Fortanet-Gomez & 2012 & $\begin{array}{l}\text { Non-linguistic features used by speakers are important to express evaluation in } \\
\text { discussion sessions in conference presentations }\end{array}$ \\
\hline Zareva & 2013 & The students stayed close to the norms of written genres to appear more scholarly \\
\hline Ayad \& Akbar & 2014 & $\begin{array}{l}\text { Variations in genre of PPT defense session presentations occur as a result of } \\
\text { community expectations and conventions, use of various modes, time and context of } \\
\text { presentation. } \\
\text { The majority of the slides were scriptural style. The students lack skill for designing } \\
\text { PPT slides. }\end{array}$ \\
\hline Morell & 2015 & $\begin{array}{l}\text { The combination of various modes makes oral presentations effective. Visuals } \\
\text { compensate lack of language deficiency. }\end{array}$ \\
\hline Rowley-Jolivet & 2015 & $\begin{array}{l}\text { Quantifiable data is handled differently in academic spoken and written text. Complex } \\
\text { data is produced via visuals. }\end{array}$ \\
\hline Mestre-Mestre & 2015 & $\begin{array}{l}\text { Images are used to support verbal delivery especially for explaining abstracts or } \\
\text { difficult concepts }\end{array}$ \\
\hline
\end{tabular}


the moves across the slides, comparing the differences in content in visuals and the verbal commentary of AOPs, how students prepare the PPT slides, the problems they face in preparing the slides and, how they link with other resources such as videos.

Table 2 summarizes the studies on the use of vi-suals in oral presentations.

There have also been studies that investigated the effect of PPT presentation on students learning and attitudes to their confidence (Song, 2013; Ang \& Mariam, 2014; Puvaneswary, 2016). The study by Ang and Mariam (2014) investigated the effect of visual design in PPT slides on students' engagement and satisfaction and found that learners have a higher engagement and satisfaction level in lecture sessions when presented a visually designed presentation. Puvaneswary (2016) employed the 'Pecha Kucha' (PK) or 'chitchat' Japanese style of PPT presentation to enhance oral presentation skills among university students and findings indicated the PK style though successful was challenging for the low proficiency level students. Students also have difficulty in preparing PPT slides and organizing content in slides (Mahfoodh, 2014). Thus, learners should be taught the skills in preparing and delivering PPT oral presentations.

Nevertheless, the previous studies mentioned have their shortcomings. Firstly, most of the visuals examined were used in conferences or defence sessions and not classroom student presentations. For classroom presentations, there were no indications given as to whether visuals formed part of the assessment criteria whereby marks were awarded for visuals. If they were included, then to what extent would they contribute towards the whole activity as a lot of time is spent in preparing visuals to the point that speakers might not have adequate time to rehearse their AOPs. Having only good visuals is insufficient as students also need to have the art of speaking and engaging with audience. Tufte (2003), one of the main critics of visuals, claims that information may be filtered when it is broken into segments to fit the bulleted point frame of the slides. In classroom presentations, this obviously is a major concern to students. Although students are required to use PPT slides, past studies do not report how they prepare PPT slides, how they condense information and avoid displaying chunks of information on their slides. As such, unnecessary information need not be displayed as overloading of information can put off the audience. Moreover, if content is weak, it might bore the audience. The readily available standard template does not help as limited content can go on one slide and having too many slides again will not attract the audience. Other aspects in relation to AOP such as role of peers and instructors, student attitudes, metacognitive strategies employed to address problems in AOP are also important. Past studies show how students worked collaboratively and negotiated with their peers and instructors to accomplish tasks and gain confidence in their AOPs (Morita, 2000, 2004; Kobayashi, 2005; Chou, 2011). As Morita (2000) aptly states, acquiring academic discourse is not a simple process of acquisition of skills and knowledge but a complex process where students have to negotiate, interact with peers and instructors. More- over, the use of metacognitive strategies helped novices to perform well (Huang, 2006) in terms of topic selection, use of effective visuals, appropriate openings, and organization of presentation. Yang (2010) concurs that the use of slide visuals is one of the learning strategies in AOP. The importance of not only visuals but other non-verbal features such as hand gestures, body posture, intonation, typology of visuals which co-occur with AOP (Hood \& Forey, 2005) and engage audience (Forey \& Feng, 2016) need to be considered.

\section{CONCLUSION}

An important observation from the literature review is that AOP is neglected in terms of genre analysis. This is perplexing as there are many studies on oral genres such as lectures, seminars, conference presentations, poster presentations, business presentations, classroom presentations, and technical oral presentations. In addition, genre analysis adopted by most studies have analysed only one section of the genre except for a few that analysed the rhetorical moves in all sections of the AOP genre. Generally the studies show that the AOP rhetorical structure includes the introduction, body, conclusion and Q \& A sections. There are obligatory and optional moves which are to be followed in a linear process but the moves are not rigid similar to other genres. In terms of the linguistic elements more studies are being conducted based on the corpus analysis approach. Perhaps this is to avoid biasness in the data analysis Moreover, minimal studies have looked at visuals in AOP. Those that did have only managed to look at one aspect of the visuals, the content of the PPT slides, the typology features (font, colour, use of animations), or the visuals and their corresponding verbal commentary. Findings of previous studies did not show if students received training in preparing visuals and to what extent they have technical knowledge in preparing PPT slides. It seems it is usually the case of relying on others or learning on their own. Technology has a profound effect on AOPs, thus as Duff (2010) postulates, studies should be conducted in both the visual and verbal modes in AOP. However, future studies in AOP need to show how visuals are prepared when investigating AOPs. By doing so, the duration in preparing visuals, reading materials and making notes for content of the slides, the technical features, and rehearsals conducted using visuals can be known. This will show if visuals are to support and not substitute the presenter. Finally, future research could also investigate moves in group presentations. To conclude, future studies need to explore in totality the rhetorical structure of the AOPs, that is, all the sections of the genre and the non-verbal aspects such as body language and corresponding visuals.

\section{REFERENCES}

Anthony, L., Orr, T and Yamazaki, A.K. (2007). Signalling Transitions in Oral Presentations: Language and Strategies. Proceedings of the IEEE International Professional Communication Conference. 
Ang, T.C. \& Mariam, M. (2014). A Study of Visual Design in PowerPoint Presentation Slide and Its Relationship with Postgraduate Learner Engagement and Satisfaction. V.78/18, 91-96. http://dx.doi.org/10.7763/IPEDR.2014.

Aguilar, M. (2004). The peer seminar, a spoken research process genre. Journal of English for Academic Purposes, 3, 55-72.

Al-Issa, A.S. \& Al-Qubtan, R. (2010). Taking the Floor: Oral presentations in EFL Classrooms. TESOL Journal 1/2, 227-246. http://dx.doi.org/10.5054/tj.2010.220425

Ayad, K. \& Akbar, A. (2014). Analyzing The Multimodality of Knowledge Presentation in Powerpoint Defense Sessions Presentations in Applied Linguistics. Asian Academic Research Journal of Social Sciences and Humanities, 1/23, 89-112.

Baker, A. (2000). Improve your communication skills. London: Kogan Page.

Bankowski, E. (2010). Developing skills for effective academic presentations in EAP. International Journal of Teaching and Learning in Higher Education, 22, 187-196.

Barrett, N.E. \& Liu, G.Z. (2016). Global Trends and Research Aims for English Academic Oral Presentations: Changes, Challenges, and Opportunities for Learning Technology. Review of Educational Research, 1-45. http://dx.doi.org/10.3102/0034654316628296

Bhatia, V.K. (1993). Analysing genre: Language use in professional settings. London: Longman.

Bhattacharyya, E. \& Zullina H.S. (2012). Communicative Competence in Technical Oral Presentation: That "Magic" Perceived by ESL Educators Versus Content Experts. WASET Online Journal, 72, 782-785.

Bloch, J. (2013). Technology and English for specific purposes. In B.Paltridge \& S.Starfield (Eds.), The Handbook of English for Specific Purposes (p.385-401). Oxford, England: Wiley-Blackwell. Bu, J.M. (2014). Towards a Pragmatic Analysis of Metadiscourse in Academic Lectures: from Relevance to Adaptation. Discourse Studies, 16/4, 449-472.

Carter-Thomas, S., \& Rowley-Jolivet, E. (2003). Analysing the scientific conference presentation (CP). A methodological overview of a multimodal genre. ASp, la revue du GERAS, 39-40, 59-72.

Charles, C., and Ventola, E. (2002). A multi-semiotic genre: the conference slide show. In E.Ventola, C., C, Shalom and S. Thompson (Eds). The language of conferencing. Frankfurt: Peter Lang.

Chen, C.W.Y. (2011). Evaluating one's own oral academic oral presentation. The Asian ESP Journal, 7/3, 5-28. Retrieved from http://www.spokenskills.com/index.cfm?type $=11 \&$ TSCategoryID $=4 \&$ TSTopicID $=640$

Cheng, S. W. (2012). “That's it for today": Academic lecture closings and the impact of class size. English for Specific Purposes, 31, 234-248.

Chou, M. H. (2011). The influence of learner strategies on oral presentations: A comparison between group and individual performance. English for Specific Purposes, 30 , 272-285.
Dubois, B. L. (1980a). Genre and structure of biomedical speeches. Forum Linguisticum, 5, 140-168.

Dubois, B.L. (1980b). The use of slides in bio-medical speeches. The ESP Journal, 1, 45-50.

Dubois, B. L. (1985). Poster sessions at biomedical meetings: Design and presentation. The ESP Journal, 4, 37-48.

Dudley-Evans, T. (2004). Genre Analysis. In K. Malmkjaer (Ed). The Linguistics Encyclopedia. pp205-208. London: Routledge.

Duff, P.A. (2010). Language Socialization into Academic Discourse Communities. Annual Review of Applied Linguistics, 30, 169-192.

Fernandez-Polo, F.J. (2014). The role of I mean in conference presentations by EFL speakers. English for Specific Purposes, 34, 58-67.

Ferris, D., \& Tagg, T. (1996). Academic listening/speaking tasks for ESL students: Problems, suggestions, and implications. TESOL Quarterly, 30/2, 297-320.

Forey, G \& Feng, D. (2016) Interpersonal Meaning and Audience Engagement in Academic Presentations. In Hyland, K \& Shaw.P. (Eds). The Routledge Handbook of English for Academic Purposes. pp. 416-430. London: Routledge.

Girard, T., Pinar, A., and Trapp, P. (2011). An exploratory study of class presentations and peer evaluations: Do students perceive the benefits? Academy of Educational Leadership Journal, 15(1), 77-93.

Hafner ,C.A. \& Miller, L. (2011). Fostering learning autonomy in English for science. A collaborative digital video project in technological learning environment. Language Learning and Technology, 15/3,68-86. Retrieved from http://.www.editlab.org/p/52231

Hewings, M. (2002). A History of ESP Through 'English for Specific Purposes'. ESP World, 1/3. Retrieved from http:// www.esp.world/info/Articles_3/Hewings_paper.htm

Huang, K. (2006). Metacognitive Strategies in Academic Oral Presentation. [Online] Available: http://sparc.nfu. edu.tw

Ho, M. (2011). Academic discourse socialization through small-group discussions. System 39/4, 437-450.

Hood, S. \& Forey, G. (2005). Presenting a conference paper: Getting interpersonal with your audience. Journal of English for Academic Purposes, 24, 291-306.

Hovane, M. (2009). Teaching presentation skills for communicative purposes. Kansai University Foreign Language Education Forum, 8, 35-49.

Hyland, K. (2005). Metadiscourse: exploring interaction in writing ( $1^{\text {st }}$ Ed.). New York: Continuum.

Hyland, K. (2009). Academic discourse: English in a global context, Continuum International Publishing Group.

Kibler, A.K., Salerno, A.S., \& Palacios, N. (2014). 'But before I go to my next step': A longitudinal study of adolescent English language learners' transitional devices in oral presentations. TESOL Quarterly, 48/2, 222-251.

Kite, Y. (2008). Language Use by Engineers at an Academic Conference. Kansai University for Human Activity Theory Research Center CHAT Technical Reports No.7, Suita: Japan. 
Kim, S. (2006). Academic oral communication needs of East Asian international graduate students in non-science and non-engineering fields. English for Specific Purposes, $25,479-489$.

King, J. (2002). Preparing EFL learners for oral presentations. Dong Hwa Journal of Humanistic Studies, 4, 401-418.

Knoblauch, H. (2008). The Performance of Knowledge: Pointing and Knowledge in Powerpoint Presentations. Cultural Sociology, 2/1, 75-97.

Kobayasi, M. (2003). The role of peer support in students accomplishment of oral academic tasks. The Canadian Modern Language Review, 59, 337-368. http://dx.doi. org/10.3138/cmlr.59.3.337.

Kress, G. \& van Leeuwen, T. (1996). Reading images: The grammar of visual design. London: Routledge.

Kress, G., \& van Leeuwen, T. (2006). Reading Images. London: Routledge

Lee, J. J. (2009). Size matters: an exploratory comparison of small- and large-class university lecture introductions. English for Specific Purposes, 28, 42-57. http://dx.doi. org/10.1016/j.esp.2008.11.001

Lee, J.J. \& Subtirelu, N.C. (2015). Metadiscourse in the classroom: A comparative analysis of EAP lessons and university lectures. English for Specific Purposes, 37, 52-62.

Lee, J.J. (2016). “There's intentionality behind it...”: A genre analysis of EAP classroom lessons. Journal of English for Academic Purposes. http://dx.doi.org/10.1016/j. jeap.2015.12.007

Magnuczne Godo, A. (2006). Are you with me? A Metadiscursive Analysis of Interactive Strategies in College Students Course Presentations. International Journal of English Studies, 6(1), 55-78.

Mahani, S., Noor Asniza, M., Norasnita, A. (2014). Engineering Technical Oral Presentation: Voices of the Stakeholders. Procedia Social and Behaviour Sciences 118, 463-467.

Mahfoodh, O.H.A. (2014). Oral Academic Discourse Socialization: Challenges Faced by International Students in a Malaysian Public University. International Education Studies, 7/2, 10-17.

Mandal, S. (2000). Presentation Skills: A Practical Guide to Better Speaking.Third Edition. California: Crisp Learning.

Marianna, Y. (2010). Analysing Communication Competence in Oral Presentations: Engineering Students Experiences. Journal of Human Capital Development, 3/1, 99-117.

Mariana, Y. \& Siti Akmar, A.S. (2013). Exploring the Engineering Communicative Challenges amongst Undergraduates. Mediterranean Journal of Social Sciences, 4/4, 59-64.

Mauranen, A. (2010). Discourse reflexivity- A discourse universal? Nordic Journal of English Studies, 9(2), 13-40.

Mestre-Mestre, Eva M. (2015). The construction of meaning in the Second Language Classroom. A Multimodal discourse analysis. Procedia-Social and Behavioral Sciences 173, 228-233.
Ming, X.Z. (2005). Developing oral presentation skills in ELT classroom. CELEA Journal, 28/2.

Mohd Azrizal, M.S. (2014). Communication Apprehension Among First-year Engineering Degree Students of Universiti Malaysia Perlis. http://dspace.unimap.edu.my

Morell, T. (2007). What enhances EFL students' participation in lecture discourse? Student. Lecturer and discourse perspectives. Journal of English for Academic Purposes, 6, 222-237.

Morell, T. (2015). International conference paper presentation: A multimodal analysis to determine effectiveness. English for Specific Purposes, 37, 137-150.

Morita, N. (2000). Discourse socialization through oral classroom activities in a TESL Graduate Program. TESOL Quarterly, 34/2, 279-310.

Morita, N. (2004). Negotiating Participation and Identity in Second Language Academic Communities. TESOL Quarterly, 38/4,573-603.

Morton, J. (2009). Genre and disciplinary competence: A case study of contextualisation in an academic speech genre. English for Specific Purposes, 28, 217-229.

Noor Hashimah A.A. (2007). ESL students' perspectives on language anxiety. Ph.D. Thesis, Universiti Putra Malaysia: Serdang.

Nor Fathiah, A. and Gurnam, K. (2013). Oral Presentation: Self-perceived Competence and Actual Performance among UiTM Business Faculty Students. Procedia Social and Behavioral Sciences, 90, 98-106. http://dx.doi. org/10.1016/j.sbspro.2011.11.383

Noor Raha, M.R., Fatimah, A., \& Hafizoah, K. (2008). Oral presentation skills for engineering students: Industry's criteria Pahang: Centre for Modern Languages and Human Sciences: University Malaysia Pahang. Noor Raha, M.R. and Sarjit, K. (2011). Technical Oral presentations in English: Qualitative analysis of Malaysian engineering undergraduates source of anxiety. Procedia Social and Behavioral Sciences, 29, 14361445.

Otoshi, J., \& Heffernen, N. (2008). Factors predicting effective oral presentations in EFL classrooms. Asian EFL Journal,10(1), 65-78. [Online] Available: http://www. asianefljournal.com/(September 29 $\left.{ }^{\text {th }}, 201322.05\right)$

Puvaneswary, M. (2016). Pecha Kucha Style PowerPoint Presentations: An Innovative Call Approach to Developing Oral Presentation Skills of Tertiary students. Teaching English with Technology, 16/1, 88-104. http://www. tewtjournal.org

Querol-Julian, M. \& Fortanet-Gomez, I. (2012). Multimodal evaluation in academic discussion sessions: How do presenters act and react? English for Specific Purposes, $31,271-283$.

Rowley-Jolivet, E. (2002). Visual discourse in scientific conference papers: A genre-based study. English for Specific Purposes, 21, 19-40.

Rowley-Jolivet, E. \& Carter-Thomas, S. (2005). The rhetoric of conference presentation introductions: context, argument, and interaction. International Journal of Applied Linguistics, 15/1, 45-70. 
Rowley-Jolivet, E. (2012). Oralising text slides in scientific conference presentations: a multimodal corpus analysis. In A. Boulton, S. Carter-Thomas, \& E. Rowley-Jolivet (Eds.), Corpus-Informed research and learning in ESP (pp. 137-165). Amsterdam: John Benjamins. http://dx. doi.org/10.1075/scl.52.

Rowley-Jolivet, E. (2015). Quantification in conference talks and proceedings articles in engineering. English for Specific Purposes, 38, 11-22.

Seliman, S. (1996). The genre and the genre expectations of engineering oral presentations related to academic and professional context. Unpublished Dissertation, University of Stirling.

Seliman, S. and Irwan Affendi, M.N (2010). The genre of the body of oral presentations delivered by English for Workplace Communication Students.(Unpublished). http://eprints.ut.my/10452

Seliman, S. and Noor Izzati, A.F. (2010). The Genre of Oral Presentations Delivered by Students Enrolled in English for Workplace Communication.(Unpublished). http:// eprints.ut.my/10126

Shalom, C. (1993). Established and evolving spoken research process genres: plenary lecture and poster session discussions at academic conferences. English for Specific Purposes, 12, 37-50.

Song, H. (2013). Effect of English Visual Presentations in Second Language Class. Proceedings of The Asian Conference on Society, Education and Technology. Osaka, Japan.

Suryani S. \& Teah, Y.Q.(2014). Communication Apprehension among Nilai College Students. Advances in Language and Literacy Studies, 5/5, 46-49. http://dx.doi. org/10.7575/aiac.alls.v.5n.5p.46

Swales, J. M. (1990). Genre analysis: English in academic and research settings. Cambridge, Cambridge University Press.

Tardy, C.M. (2005). Expressions of disciplinarity and individuality in a multimodal genre. Computers and Composition, 22/3, 319-336.

Thompson, S. (1994). Frameworks and Contexts: A Genrebased approach to analysing lecture introductions. English for Specific Purposes, 13(2), 171-186.

Thompson, S. (2003). Text-structuring metadiscourses intonation and the signalling of organisation in academic lectures. Journal of English for Academic Purposes, 2, 5-20.

Tracy, K. (1997). Colloquium: dilemmas of academic discourse. Norwood, New Jersey: Ablex.

Tufte, E.R. (2003). The Cognitive Style of PowerPoint. Chesire, CT: Graphics Press.

Ventola, E., Shalom, C., \& Thomson, S. (Eds.). (2002). The language of conferencing. Frankfurt: Peter Lang.

Vitasari, P., Muhamad Nubli, A.W., Ahmad, O. and Muhammad G.A. (2010), A research for identifying study anxiety sources among university students. International Education Studies, 3/2, 189-196.

Wecker, C. (2012). Slide presentation and speech suppressors: when and why learners miss oral information. Computers and Education, 59/2, 260-273. http://dx.doi/ org/10.1016/j.compedu.2012.01.013
Weissberg, B. (1993). The graduate seminar: Another research-process genre. English forSpecific Purposes, 12, 23-35.

Woodrow, L. (2006). Anxiety and speaking English as a second language. RELC Journal, 37, 308-328.

Wulff, S., Swales, J. M. \& Keller, K. 2009. "We have about seven minutes for questions": The discussion sessions from a specialized conference. English for Specific Purposes, 28, 79-92.

Yaacob, S. (2013) A Genre Analysis and Corpus-Based Study of University Lecture Introductions. Unpublished Ph.D. Thesis. University of Birmingham.

Yang, L. (2010). Doing a group presentation: Negotiations and challenges experienced by five Chinese ESL students of Commerce at a Canadian University. Language Teaching Research, 14/2, 141-160.

Yang, W.H. (2014). Stance and Engagement: A corpus-based analysis of academic spoken discourse across science domains. Journal of Language for Specific Purposes, $5 / 1,62-78$.

Yates, J. and Orlikowski, W. (2007). The PowerPoint Presentation and Its Corollaries: How Genres Shape

Communicative Action in Organizations. London: Cambridge University Press. Journal of the Language Teacher. 21/4, 256-277.

Yu-jung, C \& Hung-Tzu, Huang. (2015). Exploring TED talks a s a pedagogical resource for oral presentations: A corpus-based move analysis. English Teaching and Learning.39.4 Special Edition. 29-62. http://dx.doi/ org/10.6330/ETL.2015.39.4.02

Zappa-Hollman, S. (2001). Academic presentations: Exploring the second language socialization of international graduate students across disciplines. Unpublished master's thesis, University of British Columbia, Vancouver.

Zappa-Hollman, S. (2007). Academic Presentations across Post-secondary Contexts: the Discourse Socialization of Non-native English Speakers. The Canadian Modern Language Review, 63/4, 455-485.

Zareva, A. (2009). Informational packaging, level of formality, and the use of circumstance adverbials in L1 and L2 student academic presentations. Journal of English for Academic Purposes, 8, 55-68.

Zareva, A. (2011). 'And so that was it': Linking adverbials in student academic presentations. RELC Journal, 42/1, $5-15$.

Zareva, A. (2013). Self-mention and the projection of multiple identity roles in TESOL graduate student presentations: The influence of the written academic genres. English for Specific Purposes, 32, 72-83.

Zareva, A. (2016). Multi-word verbs in student academic presentations. Journal of English for Academic Purposes, 23, 83-98.Zivkovic, S. (2014). The importance of oral presentations for university students. Mediterranean Journal of Social Sciences, 15/19, 468-475.

Zivkovic, S. (2015). Introducing Students to the Genre of Presentations for Professional Purposes. Mediterranean Journal of Social Sciences, 6/2, 201-207. 